\title{
Modeling and prediction of the strength based on the time factor in tower construction
}

\author{
Król Kazimierz • Olejarczyk Krzysztof
}

Received: 2 January 2014 / Revised: 30 January 2014 / Accepted: 31 January 2014 / Published online: 2 March 2014

(c) The Author(s) 2014. This article is published with open access at Springerlink.com

\begin{abstract}
On the basis of the documentation, the finite element beam model of the Shukhov's tower has been constructed. In 1970-1971, after 50 years of exploitation, the study of the Shukhov's tower was conducted by the specialists. This study has revealed serious defects of the individual elements. It was found that the rolled profiles reaches $10 \%$ of the cross section due to corrosion and the calculated resistance of the individual components is in the range of $170 \mathrm{MPa}$, which is somewhat lower than the standard values. In the present work the time factor is taken into account as a reduction of the wall thickness of the metal profiles. In this article the state of the stress under the own weight has been examined when the wall thickness corresponds documentation (1921) and after reducing the thickness by $2 \mathrm{~mm}$ (2011). Stability analysis has been performed taking into account only the compressive load from the own weight. In this paper the main frequencies and modes of vibration of the tower model, depending on the thickness of the profile wall have been calculated. The results were obtained under the assumption that the loss of thickness of the metal profiles of the tower is accompanied by the proportional loss of the own weight.
\end{abstract}

Keywords Shukov $\cdot$ Modeling $\cdot$ FEA $\cdot$ Time factor

\section{Shukhov's tower model}

On the basis of the documentation [1] the finite element model of Shukov's tower has been constructed (Fig. 1). The

K. Kazimierz · O. Krzysztof $(\bowtie)$

Mechanical Department, Kazimierz Pulaski University of

Technology and Humanities in Radom, ul.Krasickiego 54,

26-600 Radom, Poland

e-mail: k.olejarczyk@uthrad.pl; k.olejarczyk@pr.radom.pl

K. Kazimierz

e-mail: k.krol@pr.radom.pl model consists of the six sections, which consist of 37,277 nodes and 55,849 finite elements [2]. The applied beam finite elements have 6 degrees of freedom at each node. The tower's skeleton consists of the 48 inclined interrelated components. Each of the six sections consisting of 48 segments with two $\mathrm{C}$-shaped cross-section is connected through the walls by distance sleeve.

\section{The effect of reducing the wall thickness in the stress-deformation condition of the Shukhov's tower}

In 1970-1971, after 50 years of exploitation, the survey of the Shukhov's tower steel structures was conducted by the specialists [3]. They revealed significant defects in the individual elements.

It was found that the rolled profiles rolled profiles reaches $10 \%$ of their cross section due to the corrosion and the calculated strength of individual components is in the range $170 \mathrm{MPa}$, which is somewhat lower than the standard values.

There is widespread "crevice" corrosion in the metal frame of the tower, especially at the contact elements and hard to clean connections.

In the present work, the time factor is taken into account as a reduction of the wall thickness of the metal profiles. According to $[4,5]$, the corrosion speed of the carbon steel in St3 (EN 12500, PN-EN ISO 12944-2:2000) for 10 year takes average values $5-12 \mu \mathrm{m} /$ year.

Taking the minimum value of this range we are able to predict decrease in the thickness after 90 years, to about $2.450 \mu \mathrm{m}=0.9 \mathrm{~mm}$. However you can not exclude the possibility that in the area of riveted joints the reduction of the thickness can be up to $2 \mathrm{~mm}$ or more.

The performed calculations take into account the loading by the own weight, the effects of wind, icing and snow $[6,7]$. 
Fig. 1 Finite-element model of the Shukhov's tower

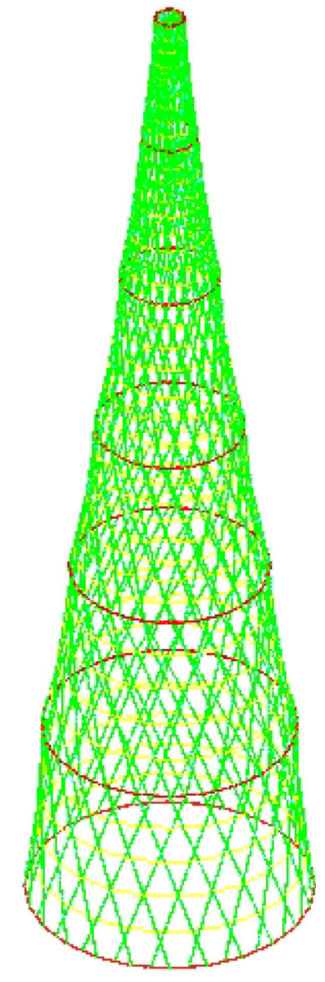

in thickness of $2 \mathrm{~mm}$ (probably in 2011) without taking into account the mass of $\mathrm{Fe}_{2} \mathrm{O}_{3}$ (Fig. 2b) and taking into account the mass of the corrosion products (Fig.2c).

Figure 3 shows the graph of the maximum stress under the own weight as a function of the thickness loss of profiles, without taking into account the mass of $\mathrm{Fe}_{2} \mathrm{O}_{3}$ (white bars) and taking into account the mass of $\mathrm{Fe}_{2} \mathrm{O}_{3}$ (gray bars). The gray area between dashed lines in the Figs. 3, 4, 5, 6 represents the area between approved level of allowable stresses in structures in 1921 (235 MPa), and the level of allowable stresses in the construction of 50-year old (170 MPa).

Figure 4 shows the maximum stress under the own weight and the wind loading as a function of the thickness loss of profiles: without taking into account the mass of $\mathrm{Fe}_{2} \mathrm{O}_{3}$ and taking into account the mass of $\mathrm{Fe}_{2} \mathrm{O}_{3}$. In six variants the allowable stress level are exceeded.

Figure 5 is a graph of the maximum stress caused by the own weight, wind, icing and snow loading as a function of the loss of the wall thickness of profiles: without taking into account the mass of $\mathrm{Fe}_{2} \mathrm{O}_{3}$, and taking into account the mass $\mathrm{Fe}_{2} \mathrm{O}_{3}$. In the six variants exceeded the allowable stress level.

\section{Stability Shukhov's tower}

installed on top of the tower.

Calculations were performed for two cases: the first case-having loss of mass proportional to the reduction of the profile thickness - corrosion products are completely removed from the structure, the second case-the reduction in the profile thickness with the conservation of the mass of corrosion products $\mathrm{Fe}_{2} \mathrm{O}_{3}$.

The Fig. 2a-c shows the dystribution of the stress only under its own weight, when the thickness profiles corresponding documentation (Year 1921) (Fig. 2a), after the reduction

Fig. 2 Distribution of the stress from the weight of the Shukhov's tower model: profiles without loss (a), the loss of $2 \mathrm{~mm}$ of the thickness without taking into account the mass of $\mathrm{Fe}_{2} \mathrm{O}_{3}$ (b), and the loss of $2 \mathrm{~mm}$ of thickness, taking into account the mass of $\mathrm{Fe}_{2} \mathrm{O}_{3}$ (c)

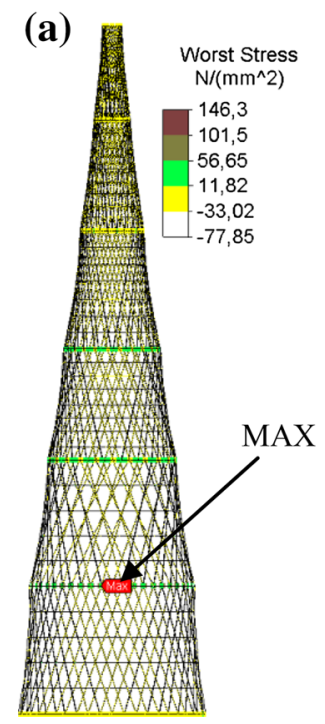

The stability analysis of the tower was performed taking into account the compressive load of its own weight and the weight placed on the top of the antenna.

Figure 6 shows the basic form of the loss of stability (buckling), together with the values of the buckling factor for the following variants: without taking into account the mass $\mathrm{Fe}_{2} \mathrm{O}_{3}$, and taking into account the mass $\mathrm{Fe}_{2} \mathrm{O}_{3}$, Fig. 7changes of this ratio as a function of the profiles thickness. The required buckling factor is 1.5 (dashed line).
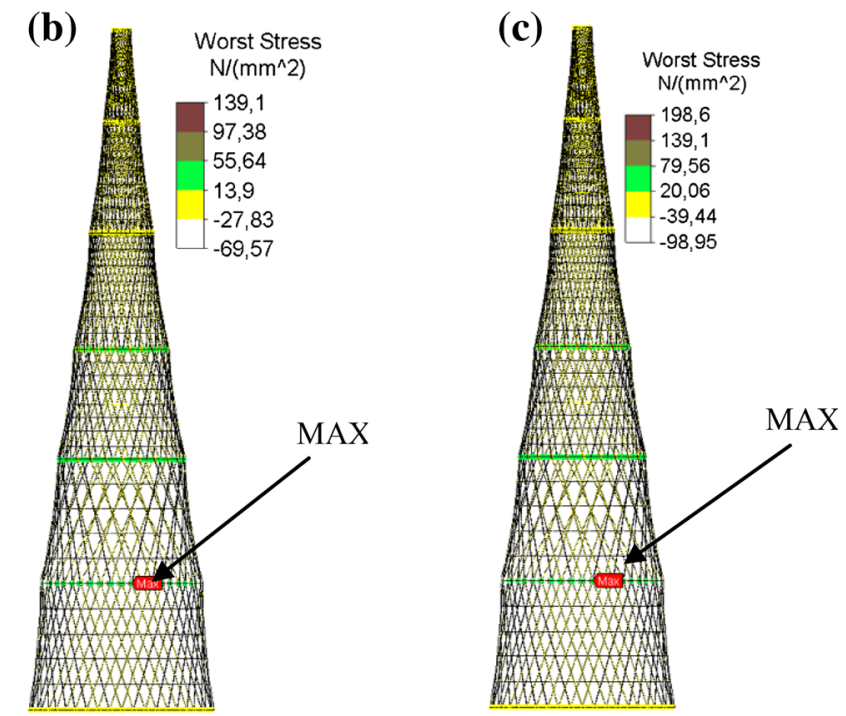
Fig. 3 Relationship between maximum stress caused by the own weight of the tower and the thickness loss of profiles of the Shukhov's tower: without taking into account the mass of $\mathrm{Fe}_{2} \mathrm{O}_{3}$ white bars and taking into account the mass of $\mathrm{Fe}_{2} \mathrm{O}_{3}$ gray bars

Fig. 4 The maximum stress loading as a function of the Shukhov's tower: without taking into account the mass of $\mathrm{Fe}_{2} \mathrm{O}_{3}$ white bars and taking into account the mass of $\mathrm{Fe}_{2} \mathrm{O}_{3}$ gray bars under its own weight and wind thickness loss of profiles of the
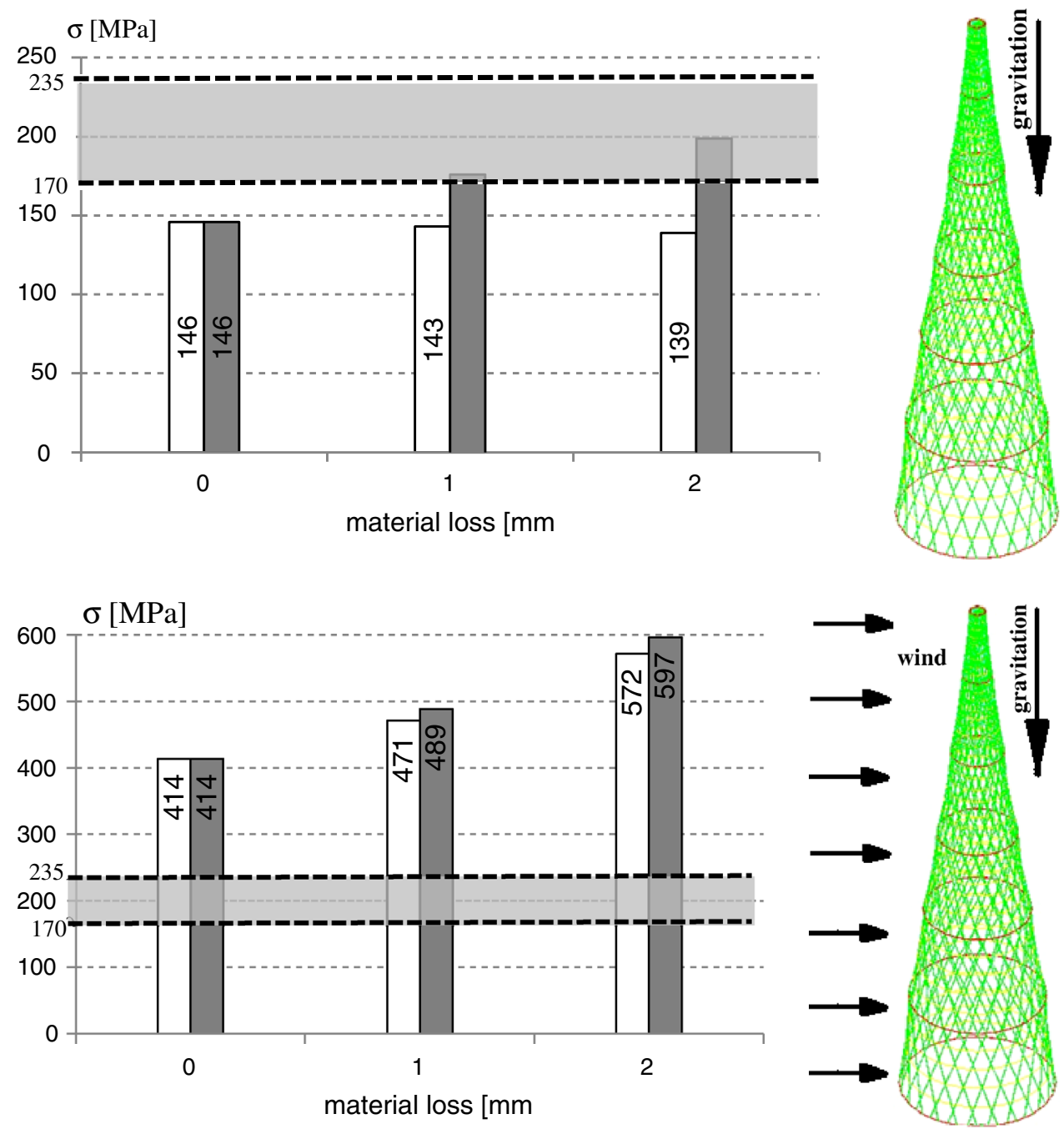

Fig. 5 The maximum stress under the own weight, wind, snow and icing loading as a function of the thickness loss of profiles of the Shukhov's tower: without taking into account the mass of $\mathrm{Fe}_{2} \mathrm{O}_{3}$ white bars and taking into account the mass of $\mathrm{Fe}_{2} \mathrm{O}_{3}$ gray bars

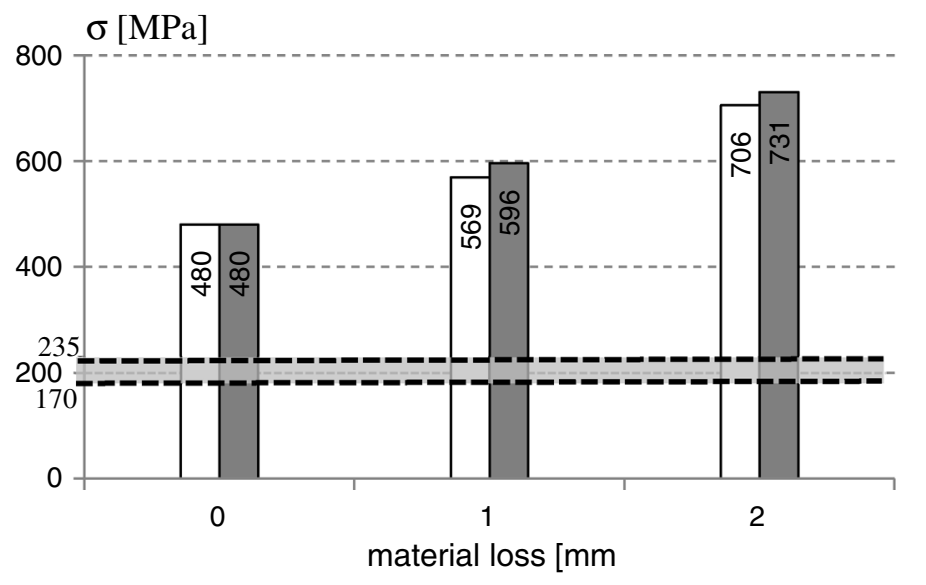

\section{Dynamic identity Shukhov's tower}

The main frequencies and modes of vibration of Shukhov's tower in dependence of the thickness loss of profiles was determined by the finite element method.
Figure 8 shows the four main modes of natural vibrations of the tower with attached mass of 2 tones ( $1 \%$ of the mass of the tower) at the top and the corresponding frequencies, and Fig. 9-natural frequency as a function of the thickness loss of profiles. 
Fig. 6 The basic form of the loss of the stability of the Shukhov's tower under its own weight and the weight of the antenna with the values of the buckling factor in case of: zero-loss (a), the loss of $2 \mathrm{~mm}$ of thickness without taking into account the mass of $\mathrm{Fe}_{2} \mathrm{O}_{3}$ (b) and taking into account the mass of $\mathrm{Fe}_{2} \mathrm{O}_{3}(\mathbf{c})$

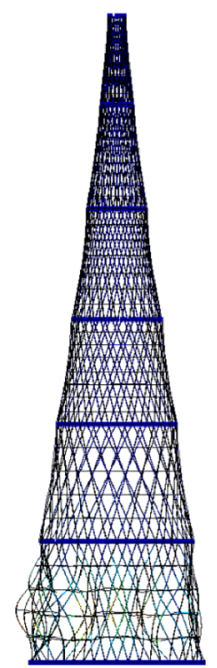

(a) Buckling factor 2,367

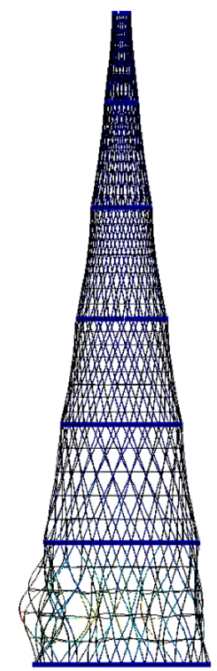

(b) Buckling factor 2,424

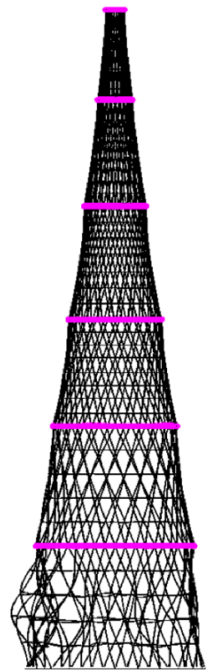

(c) Buckling factor 1,698

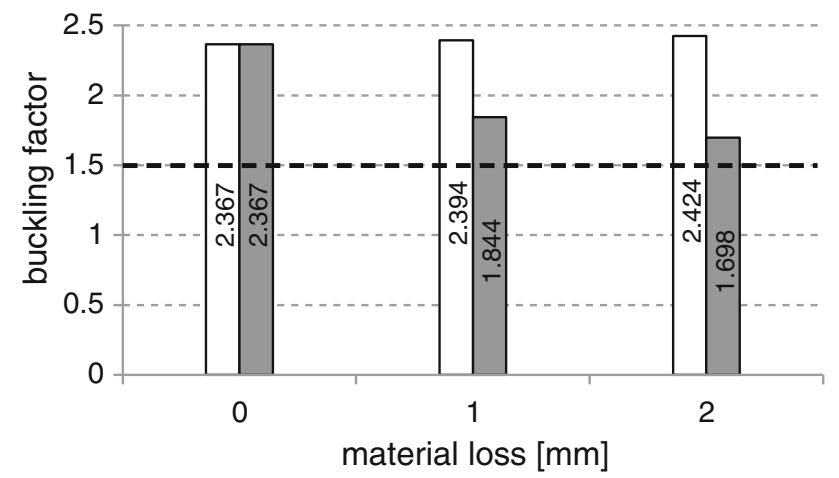

Fig. 7 Change of the buckling factor as a function of the profile thickness of the Shukhov's tower: without taking into account the mass of $\mathrm{Fe}_{2} \mathrm{O}_{3}$ white bars and taking into account the mass of $\mathrm{Fe}_{2} \mathrm{O}_{3}$ gray bars with selected value 1.5 of the accepted buckling factor

It was obtained the following basic modes of vibrationbending in vertical plane with particularly expressed displacement of the ring connecting Sect. 1 and 2 (count from the base), next-bending in the horizontal plane: elliptical flattening in the individual Sect. (2, 3 and 4) and at the connection Sect. 1 of 2, three-arm section flattening 2, 3, 4, 5 and multi armed flattened Sect. 1. In all of these modes of vibration participate the ring connecting the Sect. 1 and 2. This proves its greatest flexibility compared to the stiffness of the other rings.

\section{Analysis of the damage limits of the riveted joints}

The Shukhov's tower is a riveted construction. The limit values for damaged riveted joints by the usability criteria are given in the Table 1 on the basis of data [8].
Degradation (wear) of the riveted joints is a long tasking process and can be divided into three stages. In the first stage, all forces are transmitted by the friction at the contact surfaces of jointed elements. Then minimum stress concentration is under the rivets on the edges of the holes.

In the second stage, the forces are transmitted either by the friction at the contact surfaces of the jointed elements and directly through the rivet's cores to the wall of the holes. Then the stress concentration increases at the edges of the holes.

In the third stage (the worst) forces are transmitted only through the core rivet to the wall of the holes. Then stress concentration at the edges of the holes reaches the highest value.

As a result of the degradation of the rivets humidity and aggressive gases have easy access to the edge of the holes. This helps speed up the development of corrosion and fatigue cracks.

Riveted joints reached the second or the third stage in the construction of the Shukov's tower.

This is demonstrated by the results shown in Table 2. In the absence of some of the data it was possible to estimate the usability riveted joints after 90 years, only for criteria 5 , 7,8 and 9.

\section{Conclusions}

The above results are based on the two assumptions: firstthe thickness loss of profiles of the Shukov's tower construction accompanied by the proportional loss of its weight, its means, if the cross section is reduced by the $15 \%$ then the weight of the tower is also reduced by the same value, the 
Fig. 8 The four basic modes and vibration frequencies of the Shukhov's tower in Front view $(\mathbf{a}, \mathbf{b}, \mathbf{c}, \mathbf{d})$ and the Top view (e, $\mathbf{f}, \mathbf{g}, \mathbf{h}), \mathbf{a}, \mathbf{e}$-bending vibrations in the vertical plane of the particularly expressed displacement of the ring connecting Sect. 1 and 2; b, $\mathbf{f}$-bending vibration in the horizontal plane of the elliptical flattening in each Sect. (2, 3 and 4) and at the place of the connection Sect. 1 of 2; $\mathbf{c}$, g-bending vibration in the horizontal plane with three-arm Section flattening 2, 3, 4, 5; d, $\mathbf{h}$-bending vibrations in the horizontal plane of multi armed flattened Sect. 1

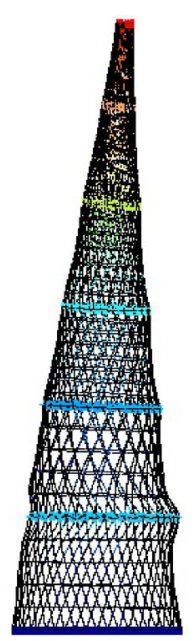

(a) $0,671 \mathrm{~Hz}$

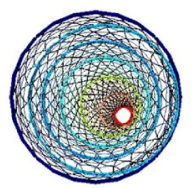

(e) $0,671 \mathrm{~Hz}$

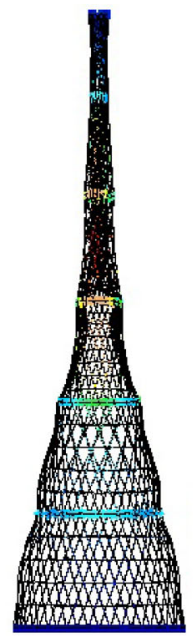

(b) $0,696 \mathrm{~Hz}$

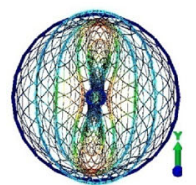

(f) $0,696 \mathrm{~Hz}$

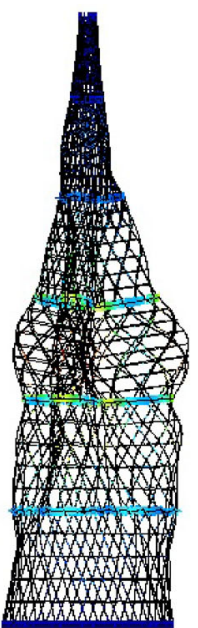

(c) $0,865 \mathrm{~Hz}$

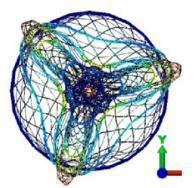

(g) $0,865 \mathrm{~Hz}$

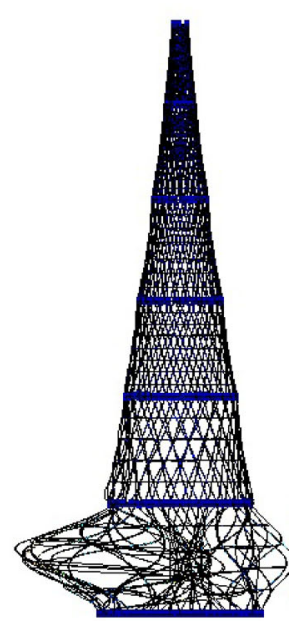

(d) $1,309 \mathrm{~Hz}$

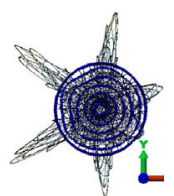

(h) $1,309 \mathrm{~Hz}$
Fig. 9 Frequencies of the four basic vibration modes as a function of the thickness loss of profiles of the Shukhov's tower

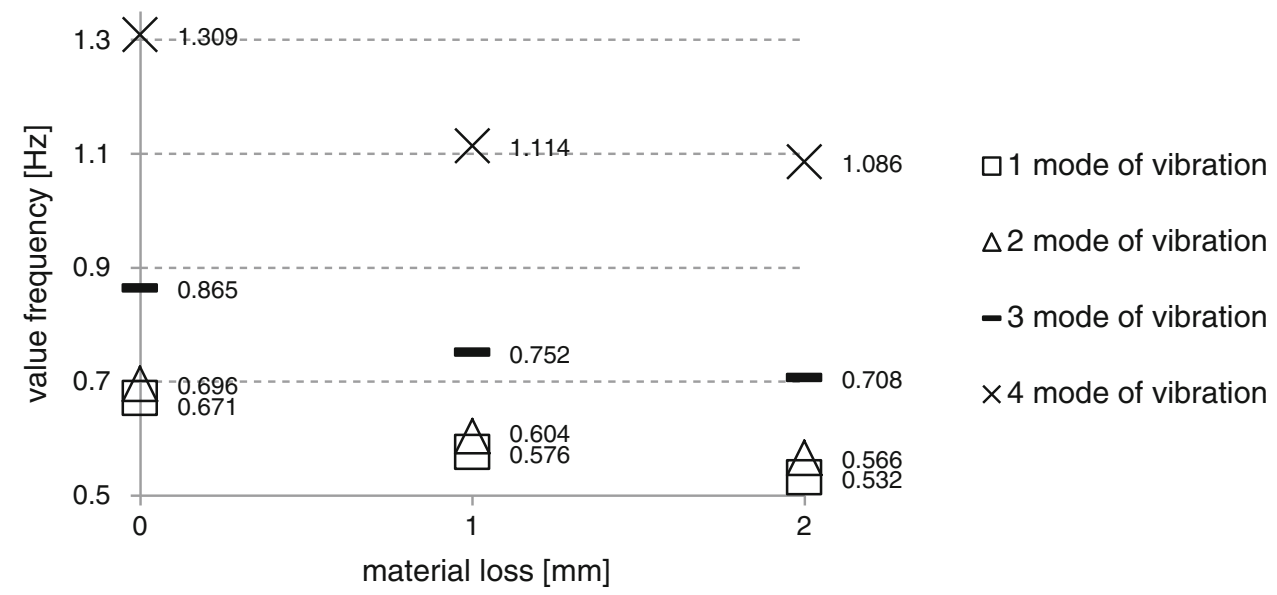

second-with the thickness loss of profiles of the structure, the weight of the corrosion product $\mathrm{Fe}_{2} \mathrm{O}_{3}$ is considered.

The calculation results presented in Figs. 3, 4, 5 are for maximum negative-extreme loads. Their analysis shows that the own weight of the structure and the wind, ice and snow loading cause a dangerous increase in a stress as a function of the loss of the wall thickness of the steel profiles the Shukov's tower.

The gray fields (Figs. 3, 4, 5, 6) which defines the area with the level of allowable stresses in the construction of the Shukov's tower allow to conclude about the danger of its further usage, especially under adverse weather conditions such as strong wind + ice (Figs. 4, 5).
The analysis of the results of buckling safety factor (Fig. 7) shows a slight increase in as a function of the loss of the material- without taking into account the mass of $\mathrm{Fe}_{2} \mathrm{O}_{3}$ and it's important reduction to a level bordering to acceptable - when the mass of $\mathrm{Fe}_{2} \mathrm{O}_{3}$ is included in the calculation.

The results of the calculations of the four main frequencies and the vibration modes indicate the dominance of the local rigidity of the tower (section stiffness) over the global stiffness. The weakest place of the tower is a conection of Sect. 1 and 2 The loss of the profiles thickness of the tower reduced the frequency in each of the four basic vibration modes. 


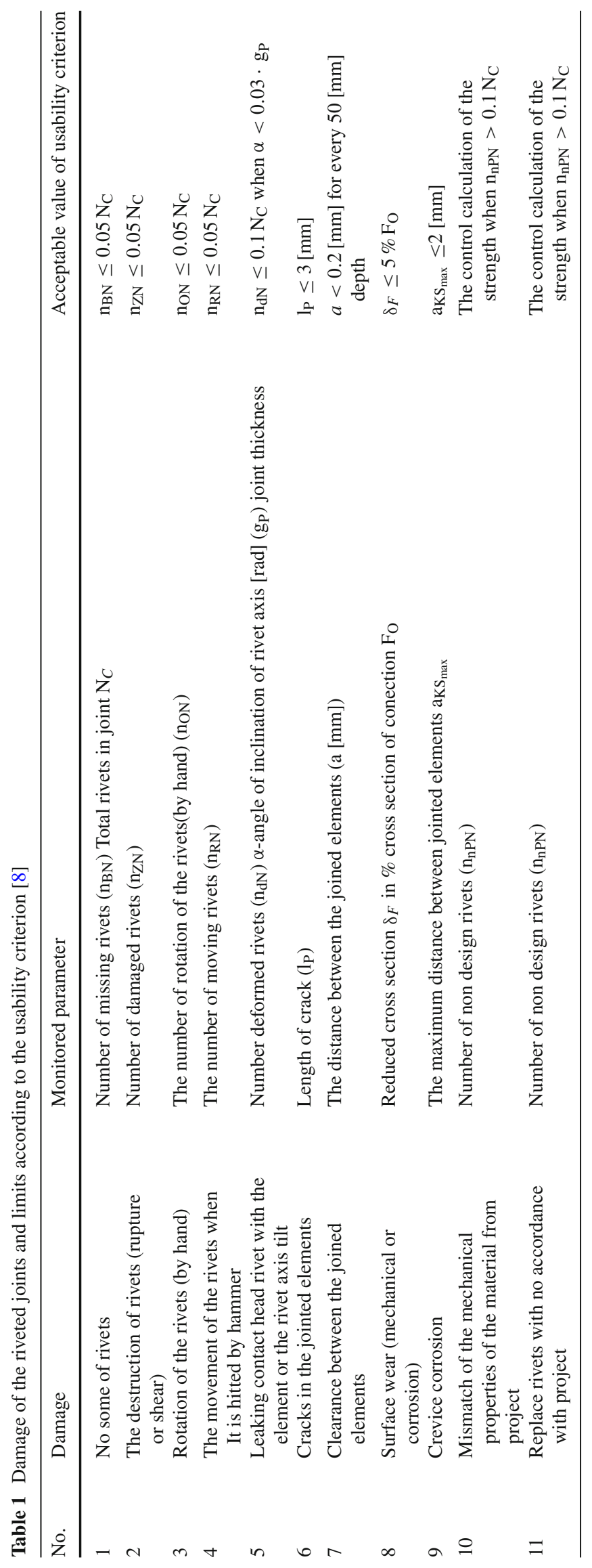




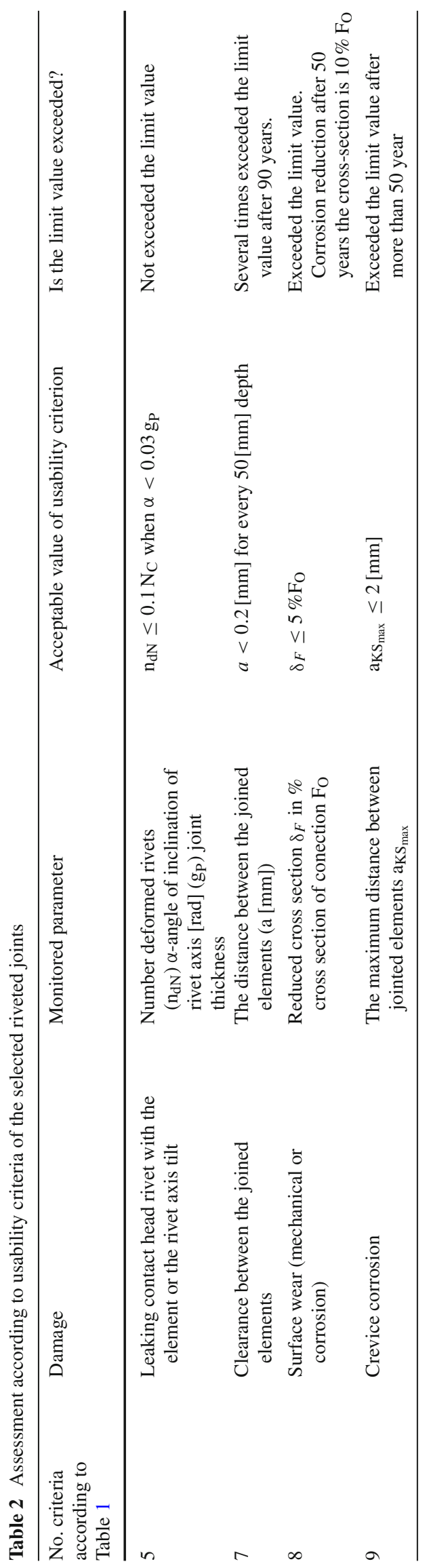

The analysis of the damage limits of the riveted joints in the Shukhov's tower by the usability criteria points to exceed the limits in three of the four criteria.

Acknowledgments The paper has been presented during 12th Conference on Dynamical Systems-Theory and Applications

Open Access This article is distributed under the terms of the Creative Commons Attribution License which permits any use, distribution, and reproduction in any medium, provided the original author(s) and the source are credited.

\section{References}

1. Archive of the Russian Academy of Sciences 1508-1-85. Drawing of W.G.Shukhov's radio tower in Moscow with height 148,5 $\mathrm{m}$ and mass 240t. N.N.T.P. Stalprommehanizatsiya SoyuzstalmostMoscow. 1919a (in russian)

2. Bielov BA, Król K (2012) Modeling and calculation of metal buildings and structures. The Ministry of Education and Science of the Russian Federation, FGBOU WPO Moscow. State. builds. Univ. -Moscow: MGSU. -160c. (Library MGSU) (in russian)

3. The history and exploitation the Shukhov's tower, http://www. computer-museum.ru/ (in russian)

4. Technical Bulletin: Atmospheric corrosion resistance of steel sheets for construction use. Centro Sviluppo Materiali S.p.A., Rome

5. Głuszko M (2008) Problems corrosion protection of steel structures and electrical equipment operating at atmospheric conditions. Doctoral dissertation. IEl, Warsaw ( in polish)

6. Building standards and rules loading and impact SNiP 2.01.07-85 (in russian)

7. Standard Technical Specifications. 400kV overhead line. Appendix 10 Designing a line of columns based on European standards. Konstancin-Jeziorna 2012. Appendix is based on the work of the Building Research Institute in 2011, which the authors are: Professor Paweł Lewiński, Ph.D. Paweł Sulik ( in polish)

8. Rd 10-197-98 Guidance document Gosgortechnadzor of Russia. Instructions for technical assessment of bolted and riveted joints of cranes (in russian) 